\begin{tabular}{c}
\hline $\begin{array}{c}\text { Brazilian Journal } \\
\text { of Chemical } \\
\text { Engineering }\end{array}$ \\
\hline
\end{tabular}

\title{
EXTRACTION, FATTY ACID PROFILE AND ANTIOXIDANT ACTIVITY OF SESAME EXTRACT (Sesamum Indicum L.)
}

\author{
R. H. R. Carvalho ${ }^{1}$, E. L. Galvão ${ }^{1}$, J. Â. C. Barros ${ }^{2}$, M. M. Conceição ${ }^{3}$ and E. M. B. D. Sousa ${ }^{\text {* }}$ \\ ${ }^{1}$ Departamento de Engenharia Química, DEQ/UFRN, Phone: + (55) (84) 3215-3769, \\ Fax: + (55) (84) 3215-3770, CEP 59072-978, Natal - RN, Brazil. \\ *E-mail: elisa@eq.ufrn.br, rique@eq.ufrn.br, elgalvao@eq.ufrn.br \\ ${ }^{2}$ Departamento de Bioquímica, CB/UFRN, CEP 59072-978, Natal - RN, Brazil. \\ E-mail: joannabarros@yahoo.com.br \\ ${ }^{3}$ Departamento de Química, DQ/UFCG, CEP 58102-012, Campina Grande - PB, Brazil. \\ E-mail: martamaria8@yahoo.com
}

(Submitted: April 19, 2011 ; Revised: November 30, 2011 ; Accepted: December 29, 2011)

\begin{abstract}
This article carried out the extraction of sesame oil by using three extraction techniques: supercritical fluid extraction (SFE), Soxhlet and sequential extraction. The SFE was performed using supercritical carbon dioxide $\left(\mathrm{SC}-\mathrm{CO}_{2}\right)$ as solvent and ethanol as cosolvent. Tests were performed at $20 \mathrm{MPa}$, $35^{\circ} \mathrm{C}$ and a flow rate of $2.5 \mathrm{~g} \mathrm{CO}_{2} / \mathrm{min}$ with a total extraction time of 210 minutes. The Soxhlet extraction was performed for 8 hours, using petroleum ether and ethanol as solvents, until the exhaustion of the oil contained in the seeds. The sequential extraction used ethyl ether, ethanol and water as solvents. The Soxhlet extraction was the most effective (58.93\%), while the SFE technique obtained $26.47 \%$ as the best result. The antioxidant activity (AA) was determined by the $\beta$-carotene/linoleic acid system, with good oxidation inhibition percentages (29.32-83.49\%) for all the extracts. The main fatty acids (FA) in sesame oil were oleic and linoleic acids.

Keywords: Supercritical extraction; Antioxidant activity; Sesame oil; Sesamum indicum L.
\end{abstract}

\section{INTRODUCTION}

Sesame (Sesamum indicum L.) is an oleaginous seed of the family Pedaliaceae, widely used as a seasoning and in bread products. In the chemical industry, its oil is used in the manufacture of margarine, cosmetics, perfumes, and many other products (Abou-Gharbia et al., 2000). It is one of the oldest and most important oleaginous crops in the world, having been cultivated for centuries in Asia and Africa, primarily for its high oil and protein content and its distinctive flavor. According to AbouGharbia et al. (2000), the largest global producers of sesame seed are India, China, and Sudan, contributing approximately $60 \%$ of world production, almost all of which is used for oil extraction.

According to Abou-Gharbia et al. (1997), its seed is composed of about $55 \%$ lipids and $20 \%$ protein and also contains vitamins and minerals. Sesame oil is rich in unsaturated fatty acids, to which is attributed its effectiveness in reducing blood cholesterol levels. It is a very rich in lecithin - a phospholipid that acts as a powerful emulsifier, facilitating the dissolution of fat in an aqueous medium (Lichtenstein and Deckelbaum, 2001). Sesame oil is also widely consumed as a nutritious food, very beneficial to health, as a cooking oil, in pharmaceuticals, in shortening and margarine, as a

*To whom correspondence should be addressed 
soap fat and as a synergist for insecticides (XU et al., 2005; Doker et al., 2010).

It is known that oils with a high content of unsaturated fatty acids are more susceptible to oxidation, undergoing rapid degradation and polymerization by free radical mechanisms (Guillen and Goicoechea, 2008). However, sesame oil has a peculiar characteristic: the presence of the natural antioxidants sesamol, sesamolin, and gammatocopherol, which gives it high oxidative stability (Corso et al., 2010).

According to Bailey (1996) and Borges et al. (1999), antioxidants are substances that have the ability to delay or inhibit oxidation processes, even when used in small amounts (10-1000 ppm), reducing the reaction rate or extending its period of induction. The effectiveness of an antioxidant is directly linked to increasing or prolonging the induction period of oxidation reactions of a substrate (lipids, proteins, carbohydrates, DNA, etc.) and can be expressed as an antioxidant index or protection factor, In the presence of antioxidants, the oxidative rates decrease due to an increased activation energy for reaction, thus increasing the "lifetime" of the substrate, serving as a parameter for the evaluation of the antioxidant activity (Borges et al., 1999).

One of the main and most used methods for antioxidant activity determination is based on the coupled oxidation reaction of $\beta$-carotene and linoleic acid. This technique, developed by Marco (1968) and modified by Miller (1971), consists of measuring the bleaching of $\beta$-carotene resulting from degradation by oxidation products of linoleic acid (Meireles et al., 2010). According to Siger et al. (2008), the DPPH method is also widely used to evaluate the antioxidant activity of different extracts. The method consists of spectrophotometric measurement of changes of the color in solution of 2,2-diphenyl-1-picrylhydrazyl (DPPH).

One way of extracting the neutral lipid fraction from food is by making use of organic solvents, which are capable of extracting free fatty acids, mono, di, and triglycerides, and also some more polar components such as phospholipids and glycolipids ( $\mathrm{Lu}$ et al., 2007). Another extraction technique used for removal of lipid material from the oleaginous matrix is supercritical extraction using solvents in supercritical conditions $\left(\mathrm{CO}_{2}\right.$, propane, ethane, ethanol, water, etc.). The most widely used supercritical fluid and most recorded in the literature is $\mathrm{CO}_{2}$, which has attracted attention because of its versatility and selectivity, in addition to its high solvation power due to its low viscosity, high penetration rate in the solid matrix, and high density.
According to Sovová et al. (2000), supercritical $\mathrm{CO}_{2}$ offers many advantages in comparison with extraction by organic solvents, because it is a clean, cheap, non-flammable, and non-toxic solvent. Moreover, it is completely separated from the extract by simply lowering the pressure, thereby obtaining a product with a high degree of purity, which is not possible when using organic solvents.

This study obtained sesame extracts by using different extraction techniques: supercritical extraction $\left(\mathrm{CO}_{2}\right.$ and $\mathrm{CO}_{2}+$ ethanol), Soxhlet extraction (petroleum ether and ethanol), and sequential extraction with different solvents (ethyl ether, ethanol and water), to compare the extraction techniques with respect to the yield and lipid profile of the extracts, thus evaluating the selectivity of the solvents used. The antioxidant potential of the extracts obtained was analyzed to establish whether the medium interferes with the inhibition of the oxidation processes of sesame oil.

\section{MATERIALS AND METHODS}

\section{Material}

The raw material used in the extractions was fresh sesame seed imported from India. The solvents and reagents used were: ethyl ether (98 wt\%, CRQ, Brazil), ethanol (99.5 wt\%, Vetec, Brazil), petroleum ether (Vetec, Brazil), $\mathrm{CO}_{2}$ (99.99\%, AGA, Brazil), $\beta$-carotene (Type I, approx. 95\% UV, Sigma), polyoxyethylene 20 sorbitan monooleate (Tween 20, Merck), linoleic acid (puriss. p.a. standard for GC $\geq 99 \%$, Sigma-Aldrich, Steinheim, Germany) and chloroform (Sigma standards, Steinheim, Germany).

\section{Preparation of Raw Material}

The moisture of the samples was determined by the AOCS method (2004). The seed was crushed and separated into Tyler series sieves, using the particle size of 24 mesh for the testing of sequential extraction, and 24 and 28 mesh $(87.5$ and $12.5 \%$ in mass, respectively) for the supercritical and Soxhlet extractions.

\section{Soxhlet Extraction}

The extractions were carried out using $5 \mathrm{~g}$ of sample in the granulometry described above for a $100 \mathrm{~mL}$ volume of solvent. The oilseed extractions were performed for 8 hours according to the procedure described by Visavadiya et al. (2009), 
taking the raw material to the complete exhaustion. The experiments were performed in triplicate to better assess the results, with petroleum ether $\left(40-60^{\circ} \mathrm{C}\right)$ and ethanol $\left(60-80^{\circ} \mathrm{C}\right)$ used as solvents in the extraction. After extraction, the solvents were evaporated under reduced pressure using a rotary evaporator (Tecnal, model TE220-Brazil) with vacuum control (Tecnal, model TE058-Brazil). The solvents were evaporated under vacuum at $40^{\circ} \mathrm{C}$ (Bozan and Temelli, 2002; Visavadiya et al., 2009). The Soxhlet used was MARCONI (MA-044/091-Brazil).

\section{Sequential Extraction}

Sequential extraction at a 1:20 ratio was used to obtain the ether extracts (low polarity), alcohol extracts (intermediate polarity), and aqueous extracts (high polarity), as indicated in Figure 1.

To prepare the ether extract, $10 \mathrm{~g}$ of the seed (24 mesh) and $200 \mathrm{~mL}$ of ethyl ether were used, and subjected to agitation at ambient temperature for 1 hour, followed by vacuum filtration. The preparation of the other extracts followed the same ratio, starting, however, from the precipitate obtained in the previous extraction (Galvão et al., 2008). The sequential extractions were performed in triplicate. The extracts obtained by this technique were used in preliminary tests of antioxidant activity (AA).

\section{Supercritical Extraction with SC-CO}

The extraction methodology is consistent with Sousa et al. (2005), in which the sample is placed in an extraction column, thereby forming a fixed bed of particles through which the supercritical fluid flows, and thus having mass transfer from the solid phase, in our case sesame seed, to the supercritical phase. The extraction cell was fed with $137.7 \pm 0.6 \mathrm{~g}$ of sesame seeds and supercritical tests were performed under the following conditions: pressure of $20 \mathrm{MPa}$, $35^{\circ} \mathrm{C}, 210$ minutes, and a rate of $2.5 \mathrm{~g} \mathrm{CO}_{2} / \mathrm{min}$, plus the addition of $5 \%$ ethanol as a cosolvent. The operating conditions adopted, such as extraction time, pressure, flow of $\mathrm{CO}_{2}$ and temperature were based on $\mathrm{Xu}$ et al. (2005) and in accordance with the operating limitations of the equipment.

The supercritical extractions were performed in triplicate, three experiments with ethanol as the cosolvent and three without a cosolvent. Figure 2 presents the supercritical extraction unit where the experiments were conducted.

The sesame oil solubility in supercritical carbon dioxide was determined by the dynamic method, which allows the use of the same equipment to study the mass transfer process (Mchugh and Krukonis, 1994; Rodrigues et al., 2002; Sousa et al., 2002).

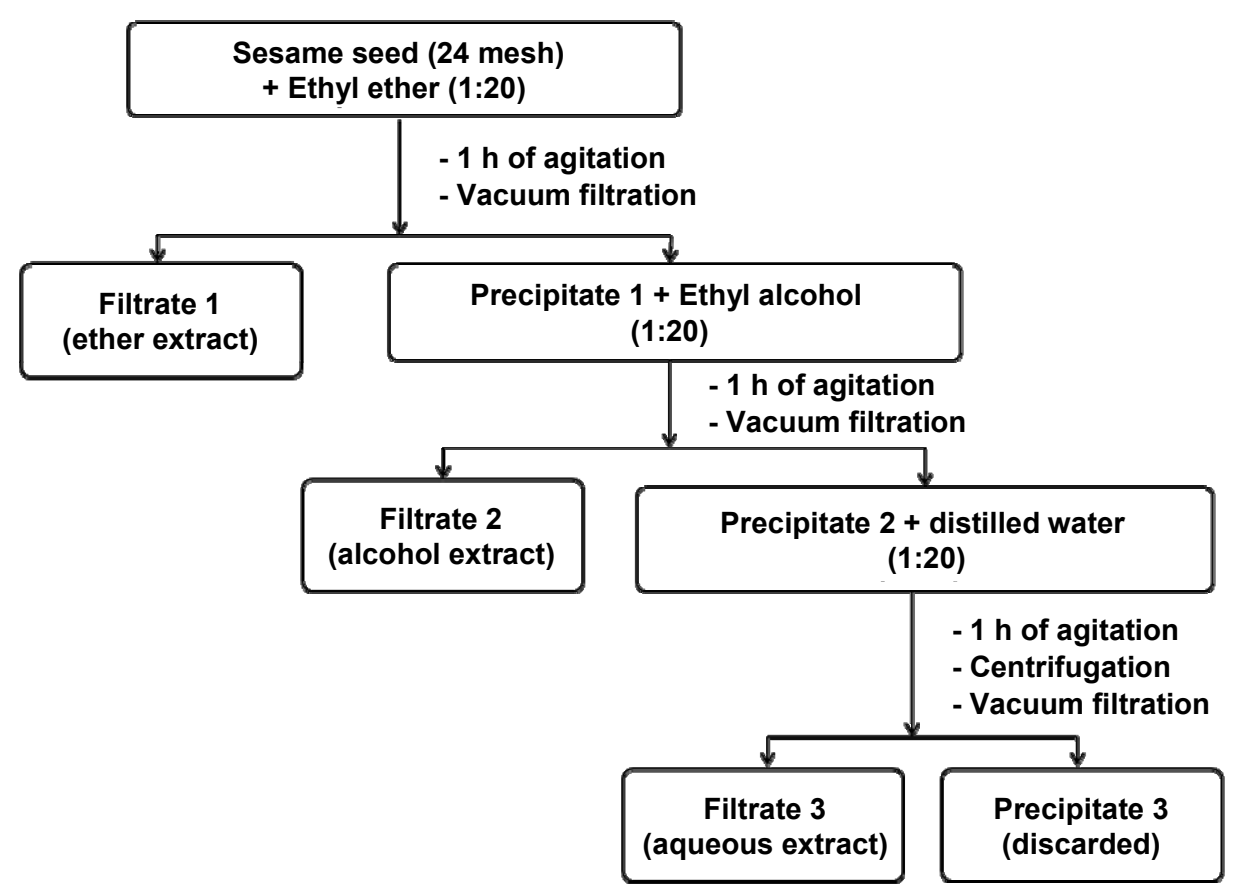

Figure 1: Sequential steps of preparing the ether extracts, alcoholic and aqueous extracts 


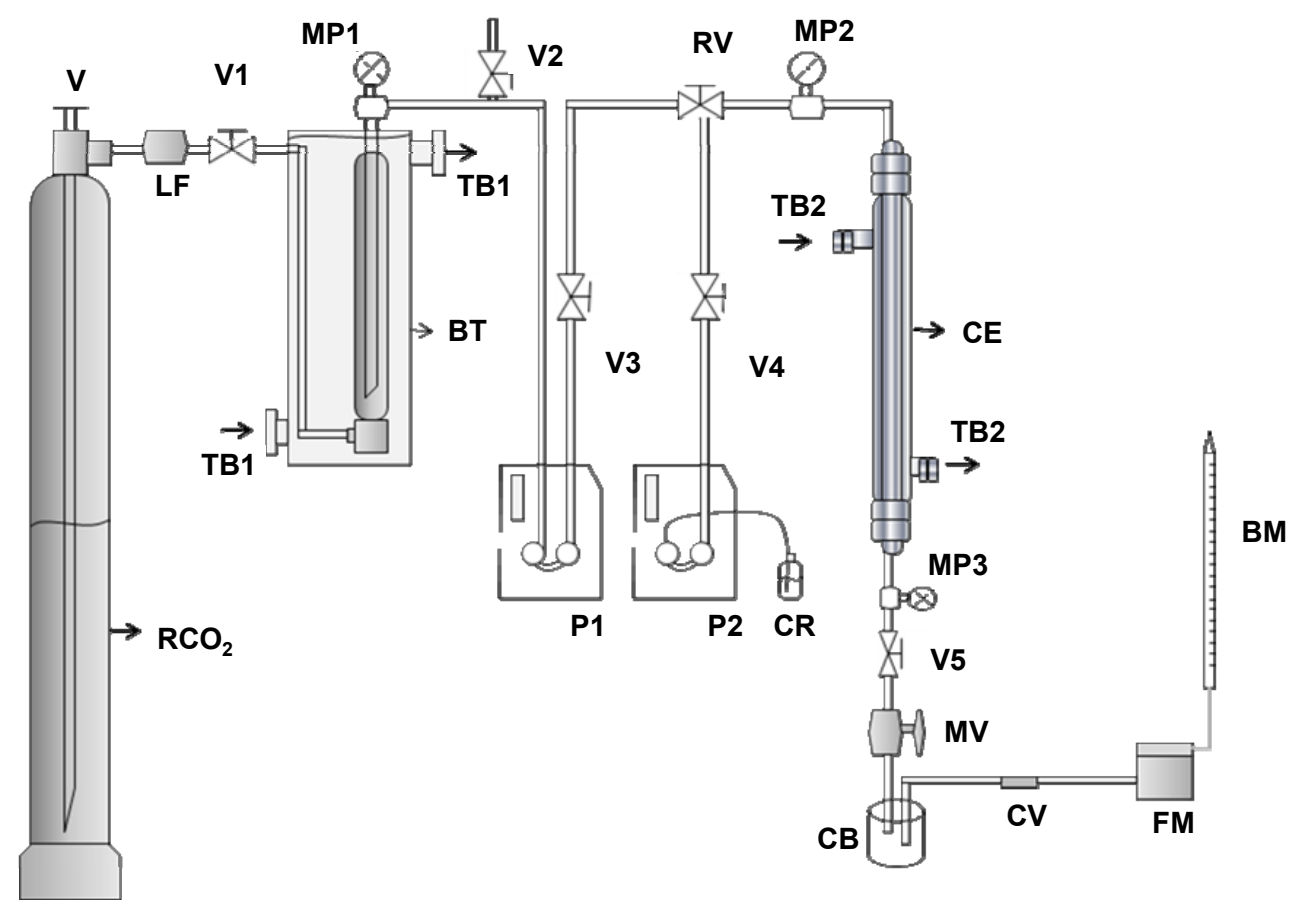

Figure 2: Layout of the supercritical extraction unit: $\mathrm{RCO}_{2}=\mathrm{CO}_{2} \operatorname{tank}(25 \mathrm{~kg}) ; \mathrm{LF}=$ Line filter; $\mathrm{BT}=$ Buffer tank; TB1 and TB2 = Thermostatic baths; $\mathrm{P} 1=$ HPLC pump for $\mathrm{CO}_{2} ; \mathrm{P} 2=$ HPLC pump for the cosolvent; $\mathrm{CE}=$ Extraction column; $\mathrm{CR}=$ Cosolvent reservoir; $\mathrm{MP} 1=$ Manometer $\left(0-100 \mathrm{Kgf} . / \mathrm{cm}^{2}\right) ; \mathrm{MP} 2$ and MP3 = Manometers $\left(0-600 \mathrm{Kgf} . / \mathrm{cm}^{2}\right) ; \mathrm{CV}=$ Volatile capture; $\mathrm{CB}=$ Collection bottle; $\mathrm{BM}=$ Bubble meter; $\mathrm{FM}=$ Flow meter; $\mathrm{RV}=$ Relief valve; $\mathrm{V}, \mathrm{V} 1, \mathrm{~V} 2$, $\mathrm{V} 3, \mathrm{~V} 4=$ Valves and MV= Micrometric valve.

In this method, in the operating conditions adopted, the $\mathrm{CO}_{2}$ passes through the column packed with material containing the oil to be extracted. The $\mathrm{CO}_{2}$ flow rate was chosen in order to ensure that the residence time in the column is enough to make the fluid saturated with oil in the output of the extraction column. Thus, when the oil concentration in the solvent at the output of the extractor remains constant for a determined mass of solvent used, one can say that the equilibrium conditions prevail at the output of the extractor and that this concentration corresponds to the oil solubility in the supercritical carbon dioxide. By observing the experimental extraction curve "total mass of oil extracted (or mass of solvent) versus extraction time", the extraction period in which the solvent exits the extractor saturated with solute corresponds to the linear phase of this curve, and the slope of the line (when the mass of solvent is used on the abscissa) corresponds to the value of the oil solubility under the operating conditions (Monteiro et al., 1997; Rodrigues et al., 2002; Sousa et al., 2005).

\section{Obtaining the Fatty Acids}

The extracts were converted to fatty acid methyl esters (FAME) for subsequent chromatographic analysis. Obtaining fatty acid methyl esters (FAME): Initially, the oil samples obtained were esterified according to the AOAC 963-22 (2000) method and injected onto the chromatograph. The chromatographic conditions followed the procedures described by Moreira and Mancini Filho (2004). The analyses were performed on a GC 17A gas chromatograph (SHIMADZU) with Class GC software. The column used was SUPELCOWAX 10 fused silica (polyethylene glycol, $30 \times 0.25 \mathrm{~mm} \times$ $0.25 \mu$ ). The chromatographic conditions followed the schedule: 1) Temperature gradient: the initial temperature was $170^{\circ} \mathrm{C}$, with heating at $1^{\circ} \mathrm{C} / \mathrm{min}$ up to $225^{\circ} \mathrm{C}$, remaining at this temperature for 10 minutes; 2) Vaporizer temperature: $250^{\circ} \mathrm{C}$; 3) Detector temperature: $270^{\circ} \mathrm{C}$; 4) Carrier gas: Helium $(\mathrm{He})$, with a flow of $1 \mathrm{~mL} / \mathrm{min}$ and division ratio of the sample in the injector: 1/50. Fatty acid 
identification in the samples was done through comparison with Sigma standards (Steinheim, Germany).

\section{Antioxidant Activity (AA)}

The extracts obtained were used in tests to determine the antioxidant activity in the $\beta$-carotene/ linoleic acid system, which evaluates inhibition of the formation of free radicals generated during the peroxidation of linoleic acid.

The methodology adopted to determine the antioxidant activity of sesame extracts was developed by Marco (1968) and modified by Miller (1971). This in vitro method of substrate cooxidation uses $\beta$-carotene and linoleic acid as oxidizing agents and Tween as an emulsifying agent. This method is based on spectrophotometric measurements of $\beta$-carotene bleaching (oxidation) induced by the oxidative degradation products of linoleic acid.

The concentrations used in the tests were proposed by Moreira and Mancini Filho (2003). Preparation of the reactive mixture was carried out in a $250 \mathrm{~mL}$ Erlenmeyer flask, using $40 \mu \mathrm{L}$ of linoleic acid, $50 \mu \mathrm{L}$ of $\beta$-carotene $(20 \mathrm{mg} / \mathrm{mL}$ of chloroform), $0.5 \mathrm{~mL}$ of Tween 20 , and $1 \mathrm{~mL}$ of chloroform to make the mixture homogenous. The chloroform was evaporated after the homogenization procedure. Distilled water (previously treated by bubbling oxygen for 30 minutes) was added to this chloroform-free mixture until a solution with optical density between 0.6 and 0.7 at a wavelength of $470 \mathrm{~nm}$ was obtained, measured with a spectrophotometer (395-D Digital UV-VIS Coleman Spectrophotometer). Different volumes of extract (50, 100, and $200 \mu \mathrm{L})$ were added to test tubes containing the reactive mixture. The system obtained was homogenized and maintained at $45^{\circ} \mathrm{C}$ in a water bath to accelerate the oxidation reactions and initiate $\beta$-carotene bleaching. Spectrophotometer readings were performed immediately and repeated every 15 minutes for a period of one hour. This procedure was repeated for all extracts. All the determinations were performed in duplicate and accompanied by a control without antioxidants.

The results are expressed as an oxidation inhibition percentage (\%I), which is calculated by considering the decay of the control's optical density (Dc) as $100 \%$ oxidation (Equation (1)).

$\% \mathrm{I}=\left(\frac{\mathrm{Dc}-\mathrm{Dam}}{\mathrm{Dc}}\right) 100$
The decrease in optical density (Dam) is given by $\mathrm{Dam}=\mathrm{Abs}_{\text {initial }}-\mathrm{Abs}_{\text {final }}$ (absorbance variation in the sample) and of the control $\mathrm{Dc}=\mathrm{Abs}_{\text {initial }}-\mathrm{Abs}_{\text {final }}$ (absorbance variation in the control, i.e., without the substance that inhibits oxidation).

Based on these data, a comparative study of the sesame extract kinetic behavior with a synthetic antioxidant BHT was performed. This study is important in order to provide information on how the natural antioxidants present in the sesame extracts curb the oxidative process in the $\beta$-carotene/linoleic acid system.

\section{Kinetic Study of Antioxidant Activity (AA)}

The efficiency of extract antioxidant activity was estimated by the method of tangents in two parts of the kinetic curves. This method was initially described by Yanishlieva and Marinova (1995) and, afterwards, modified by Moreira and Mancini Filho (2003).

In the first part of the curve (between 15 and 45 minutes after initiating the reaction), the antioxidant efficiency in blocking the chain reaction through interaction with the peroxide radicals was measured. This efficiency was measured through the ratio between the tangents of the kinetic curves for the extract and for the control with no antioxidant. The values obtained were designated factor 1 (F1). In the second part of the curve (between 75 and 105 minutes after onset of the reaction), the ability of the antioxidant to participate in other reactions during the oxidative process was measured. This measure was obtained as the ratio between the tangents of the kinetic curves for the extract and for the control with no antioxidant. The values obtained were designated factor 2 (F2). The results obtained for F1 and F2 may be larger or smaller than 1 . If the result is higher than 1 , then the antioxidant can have an opposite effect, i.e., act as a pro-oxidant (PO), contributing to the oxidative reactions.

\section{Statistical Analysis}

The extractions were performed in triplicate and the means are reported. The FA composition analysis of each extract was performed in duplicate and the means were reported. ANOVA of the results was performed using Statistical Software, Version 6. Multiple comparison of the means was performed by the t-test for dependent samples at the $\mathrm{P}=0.05$ level, to compare the yield data of the extractions (Soxhlet and SFE) and compare the composition data of the extracts obtained by all extraction techniques. 
RESULTS AND DISCUSSION

\section{Yield of the Extractive Processes}

Table 1 presents the yields (oil mass/raw material mass) of the extractions for sesame oil, obtained from samples with a moisture content of $3.20 \%$ and an average particle diameter of $0.69 \mathrm{~mm}$. The yields reported are the average of three experiments.

Soxhlet extraction results revealed that ethanol was as a better solvent than petroleum ether for the sesame extracts. The maximum yield achieved was $58.93 \%$ when using ethanol as a solvent and $47.54 \%$ for petroleum ether. According to Péres et al. (2006), this result can be explained by the greater interaction between unsaturated fatty acids and polar solvents like ethanol, than with non-polar solvents like petroleum ether. The supercritical technique (SFE) achieved the best result (26.47\%) when $\mathrm{CO}_{2}$ and ethanol were used, thus increasing its performance in comparison to extraction without the use of a cosolvent (14.19\%). The addition of $5 \% \quad(\mathrm{v} / \mathrm{v})$ ethanol cosolvent to the process nearly doubled the extraction yield. The solubility reached in experiments with co-solvent was $0.12 \mathrm{~g}$ oil $/ \mathrm{g} \mathrm{CO}_{2}$, while in experiments without cosolvent the solubility was approximately $0.10 \mathrm{~g}$ oil $/ \mathrm{g} \mathrm{CO}_{2}$.

Considering that Soxhlet extraction recovers the maximum amount of oil extractable from the seed, the best yield value obtained with the SFE technique was approximately $45 \%$ of the total extractable oil. According to Bozan and Temelli (2002), the conventional extraction method using organic solvents such as petroleum ether, for example, also extracts phospholipids, pigments, and unsaponifiable substances, giving a higher extraction yield. However, the analysis of Figure 3 shows there was no stabilization of the kinetic curve in the SFE with cosolvent, indicating that better yields could be obtained by longer extraction periods.

The statistical analysis using the t-test for dependent samples showed that there was a significant difference $(\mathrm{P}<0.05)$ between the oil recovery obtained by the Soxhlet and $\mathrm{SC}-\mathrm{CO}_{2}$ extraction techniques. The yields of the Soxhlet extractions were significantly $(\mathrm{P}<0.05)$ higher than those obtained by supercritical extractions, which is consistent with Bozan and Temelli (2002) for conventional extractions using organic solvents. The results of extractions using the Soxhlet technique and hexane as an extractive solvent are reported in the literature for sesame extracts. Corso et al. (2010) obtained yields of $52.6 \%$ for a 20 hour extraction process. Elleuch et al. (2007) obtained a lower yield, $41.46 \%$ over 4 hours, using raw material from Sudan. These results, when compared to those found in this study (58.93\% using ethanol as a solvent and $47.54 \%$ for petroleum ether), indicate that ethanol may be a more appropriate solvent for solubilizing sesame extracts, since its use resulted in a considerable yield increase with both extraction techniques studied.

Despite not having achieved high yields, sesame oil extraction using supercritical fluids is shown to be an important alternative. The low critical temperature of $\mathrm{CO}_{2}$ allows its use in the supercritical state, and it is adequate for extraction of the active principle of complex natural products, since most of these compounds are hydrolyzed and thermolable. Another important factor in this technique is that the product is free of contamination, since $\mathrm{CO}_{2}$ is a nontoxic, contamination-free solvent (Mchugh and Krukonis, 1994).

Studies of supercritical extraction using sesame as a raw material were also found in the literature; however, $\mathrm{CO}_{2}$ or propane were used as solvent: Corso et al. (2010) obtained an extraction yield of $35 \%$ using $\mathrm{CO}_{2}$ as solvent at 250 bar pressure, a temperature of $40^{\circ} \mathrm{C}, 510$ minutes. In tests with propane, a $34.1 \%$ extraction yield was obtained at 120 bar pressure, $60^{\circ} \mathrm{C}$, over 50 minutes. Comparing the results of this study with the ones found in the literature, it was possible to observe that the extraction yields are lower $(26.47 \%)$. However, it should be considered that the operating temperature used was milder (which lowers costs) and the extraction time was also shorter.

Table 1: Average yield (\%) of the supercritical fluid extraction (SFE) and Soxhlet for the sesame extracts.

\begin{tabular}{|l|c|c|c|c|}
\hline Technique & Solvent & $\begin{array}{c}\text { Cosolvent } \\
\mathbf{( 5 \% )}\end{array}$ & $\begin{array}{c}\text { Yield g oil/100 g dry } \\
\text { sample (\%) }\end{array}$ & SD\% $^{\mathbf{a}}$ \\
\hline $\mathrm{SFE}$ & $\mathrm{SC}-\mathrm{CO}_{2}$ & - & 14.19 & 0.83 \\
$\mathrm{SFE}$ & $\mathrm{SC}-\mathrm{CO}_{2}$ & Ethanol & 26.47 & 0.41 \\
Soxhlet & Ethanol & - & 58.93 & 0.58 \\
Soxhlet & Petroleum ether & - & 47.54 & 0.76 \\
\hline
\end{tabular}

${ }^{\text {a }}$ Percent standard deviation. 
Figure 3 presents the kinetic curve behavior (oil mass extracted as a function of time) in the supercritical extractions performed with and without the use of ethanol as a cosolvent. First, it can be seen that, for the test performed without the use of cosolvent, $80 \%$ of the extracted oil was obtained in the first 60 minutes, with a gradual decrease in mass of the oil recovered over the remaining 150 minutes. For the tests performed with the addition of ethanol as a cosolvent, the recovery percentage reached $59 \%$ for the first 60 minutes, with a less pronounced decay of the oil mass extracted during the process, causing the oil extraction to last longer.

The extraction rates of the tests performed in the presence of ethanol as extractive cosolvent were much higher than those of tests performed with $\mathrm{CO}_{2}$ only (Montarini et al., 1996; Odabasi and Balaban, 2002; Tanaka et al., 2004). This behavior demonstrates the greater solvation power of $\mathrm{SC}-\mathrm{CO}_{2}$ when associated with alcohol and, as a consequence, a larger amount of oil was obtained at the end of the extraction process (as evidenced by the oil mass accumulated over time).

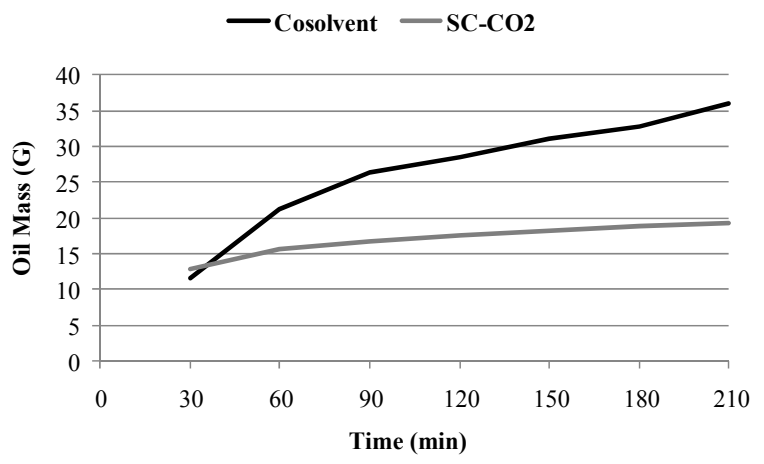

Figure 3: Kinetic curve of supercritical extraction of the sesame oil (sesamum indicum L.)

\section{Obtaining the FA of Sesame Oil}

The fatty acid profile of sesame oil is presented in Table 2. The sesame oil obtained by SFE under different conditions, Soxhlet extraction with different solvents and sequential extraction contained oleic (38.1-43.2\%), linoleic (36.2-43.1\%), stearic (5.3$13.3 \%)$ and palmitic acid (4.8-11.5\%). Regarding Soxhlet extraction, the main components were oleic and linoleic acids with average percentages of around $42.0 \%$ and $39.0 \%$, respectively (Table 2). Those results are similar to the ones previously reported by Elleuch et al. (2007) and Corso et al. (2010), who obtained a profile of fatty acids with predominantly linoleic (43-46.8\%) and oleic (35$36.4 \%$ ) acids by the same extraction technique.

Table 2: Fatty acid composition of the sesame oil samples extracted by Soxhlet, SFE and sequential extraction.

\begin{tabular}{|l|r|r|r|r|r|}
\hline \multicolumn{7}{|c|}{ Composition (\%) } \\
\hline Fatty Acid & \multicolumn{2}{|c|}{ Soxhlet } & \multicolumn{2}{|c|}{ Supercritical-CO } & Sequential \\
\hline Palmitic & $4.8^{\mathrm{a}}$ & $11.0^{\mathrm{b}}$ & $11.2^{*}$ & 11.5 & 9.2 \\
Stearic & $13.3^{\mathrm{a}}$ & $6.5^{\mathrm{b}}$ & $6.9^{*}$ & 7.1 & 5.3 \\
Oleic & $43.2^{\mathrm{a}}$ & $40.3^{\mathrm{b}}$ & $40.8^{*}$ & 41.3 & 38.1 \\
Linoleic & $36.2^{\mathrm{a}}$ & $41.8^{\mathrm{b}}$ & $41.2^{*}$ & 39.8 & 43.1 \\
Other & $2.4^{\mathrm{a}}$ & $0.3^{\mathrm{b}}$ & 0.1 & 0.3 & 1.5 \\
\hline
\end{tabular}

${ }^{*}$ Use of cosolvent ( $5 \%$ ethanol)

${ }^{a}$ Oil obtained by using petroleum ether as solvent

${ }^{\mathrm{b}}$ Oil obtained by using ethanol as solvent

According to Table 2, considerable differences can be observed in the composition of the sesame oil obtained by Soxhlet extraction. A statistical analysis using the t-test for dependent samples showed that there is a very significant difference $(\mathrm{P}<0.05)$ in the oil compositions obtained with ethanol and petroleum ether. When the oil was obtained with ethanol, the percentage of palmitic acid is more than double the percentage of the same acid in the oil obtained with petroleum ether $(11.0 \%$ and $4.8 \%$ of C16:0, respectively). When compared to stearic acid, the roles are reversed. The percentage of this acid doubles when using petroleum ether instead of ethanol as solvent, rising from $6.5 \%$ to $13.3 \%$ of C18:0, demonstrating that such behavior may indicate selectivity of a specific solvent for certain fatty acids, which is consistent with Péres et al. (2006).

With respect to SFE extracts, the composition of the fatty acids from the extracts obtained with the addition of a cosolvent was similar to the ones obtained only with $\mathrm{CO}_{2}$, but significant differences were observed $(\mathrm{P}<0.05)$. By comparing the extracts of the Soxhlet and SFE technique, it is possible to observe similarities and differences in terms of FA composition. The concentrations of saturated and polyunsaturated FA are significantly different $(\mathrm{P}<0.05)$ when comparing the two techniques. The palmitic acid percentage obtained via Soxhlet with petroleum ether was significantly $(\mathrm{P}<0.05)$ lower than those obtained by $\mathrm{SC}-\mathrm{CO}_{2}$ and Soxhlet with ethanol. On the other hand, the percentage of stearic and oleic acid obtained with petroleum ether was significantly $(\mathrm{P}<0.05)$ higher than those obtained by $\mathrm{SC}-\mathrm{CO}_{2}$ and Soxhlet with ethanol.

Comparing the results of the sequential extraction technique versus the Soxhlet and supercritical 
extraction, no significant differences were observed $(\mathrm{P}>0.05)$ in the concentration of stearic and linoleic acids in the oils obtained by Soxhlet with ethanol as solvent and by $\mathrm{SC}-\mathrm{CO}_{2}$ with and without cosolvent. In the oil obtained via Soxhlet with petroleum ether and via sequential extraction, the difference in concentration of saturated fatty acids and polyunsaturated was statistically significant $(\mathrm{P}<0.05)$. However, we cannot conclude that the use of these techniques and the use of petroleum ether as solvent actually changes the composition of the oil obtained. This is because the P value obtained in the statistical analysis was almost equal to the $\mathrm{P}$ value for the level of statistical significance adopted $(\mathrm{P}=0.05)$.

Also according to Table 2, by analyzing the composition of polyunsaturated fatty acids from the samples, it was possible to verify that the fatty acid profile is consistent for this oil and in accordance with Doker et al. (2010), with the major components C18:1 and C18:2 being approximately $81 \%$ of the sample. The results in Table 2 are also consistent with those reported by Corso et al. (2010), with linoleic $(46.2 \%)$ and oleic $(36.1 \%)$ acids being the major components in the oil extracted with $\mathrm{SC}-\mathrm{CO}_{2}$ and linoleic (45.7\%) and oleic (37.8\%) acids the major components in the oil extracted with propane.

\section{Antioxidant Activity of the Sesame Extracts}

\section{Preliminary Tests}

Preliminary studies of the antioxidant activity (AA) were performed with the extracts obtained by sequential extraction. These preliminary tests were performed in order to evaluate the effectiveness of the $\beta$-carotene/linoleic acid method to be used for other extracts (SFE and Soxhlet). The results obtained from these tests were satisfactory, with an oxidation inhibition percentage of $57.32 \%$ for the ether extract (ethylic ether), 32.22\% for the alcoholic extract (ethanol) and $53.14 \%$ for the aqueous extract (volume of extract used of $100 \mu \mathrm{L}$ ). The sequential technique was used in the preliminary tests because of its rapid implementation and the use of solvents of different polarities, which formed the basis for the choice of solvents used in the other extraction techniques evaluated (SFE and Soxhlet).

The kinetic curves of oxidation inhibition (Figure 4) were constructed to clarify the mechanism of antioxidant action of the phenolic compounds present in sesame extracts. The results are expressed according to the oxidation inhibition percentage of the $\beta$-carotene/linoleic acid system in relation to their concentration, $100 \%$ oxidation being of the control without antioxidants. Figure 3 displays the kinetic behavior of the sesame extracts (volume of $100 \mu \mathrm{L}$ ) obtained by sequential extraction compared to the control and the synthetic antioxidant BHT.

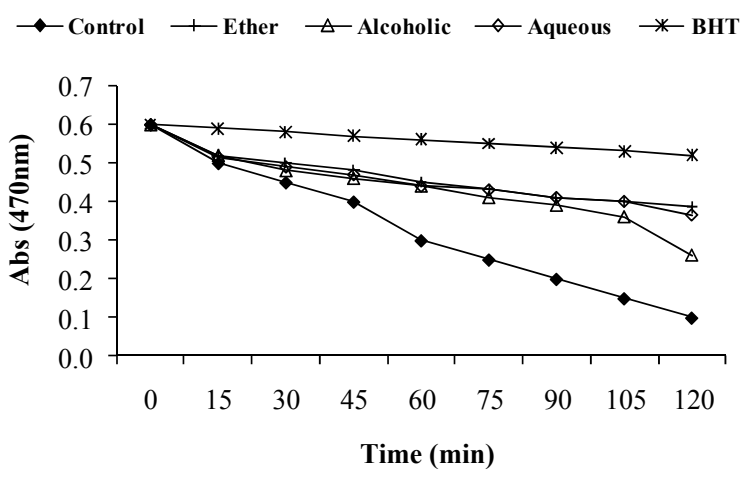

Figure 4: Antioxidant activity of the ether, alcoholic and aqueous extracts of sesame seeds and comparison with that of BHT (volume of $100 \mu \mathrm{L}$ )

Figure 4 shows that the antioxidant activity (AA) in relation to time was very similar for the ether and aqueous extracts, which indicates that protection with respect to oxidation occurs in a similar manner for both extracts. For the alcohol extract, a decrease in protection is observed from 90 minutes on. For comparison, the activity of the synthetic antioxidant BHT was determined at the same concentration used in the extracts and displayed better inhibition of the oxidative process.

In view of the satisfactory results obtained for the antioxidant activity of extracts from the sequential extraction, the $\beta$-carotene/linoleic acid method was used to investigate the AA of the other extracts (SFE and Soxhlet). The volume range of extract used was increased $(50,100$ and $200 \mu \mathrm{L})$ in order to observe the influence of the volume of extract on the results.

\section{SFE and Soxhlet Extracts}

Regarding supercritical and Soxhlet extractions, after obtaining sesame extracts with solvents of different polarities, the presence of antioxidant activity in the different extracts was evaluated. The results showed different levels of oxidative process inhibition and are shown in Figure 5.

The ether extract (Soxhlet with petroleum ether) was the one that best solubilized substances with antioxidant properties. It presented 51.12, 75.78 and $83.49 \%$ oxidation inhibition in the extract volumes of 50, 100 and $200 \mu \mathrm{L}$, respectively. The alcoholic extract (Soxhlet with ethanol) presented an inferior 
performance, with oxidation inhibition percentages of $29.32,58.28$ and $71.36 \%$ for the extract volumes of 50,100 and $200 \mu \mathrm{L}$, respectively. It is important to point out that petroleum ether is a better extraction solvent than ethanol ( $\mathrm{Lu}$ et al., 2007), which could have contributed to increase the solubilization of compounds with oxidant principles. The high oxidative stability of the oil can be attributed to the presence of tocopherols, which inhibit lipid peroxidation, and of endogenous antioxidants such as sesamin and sesamolin, better known as lignans (Hemalatha, 2007).

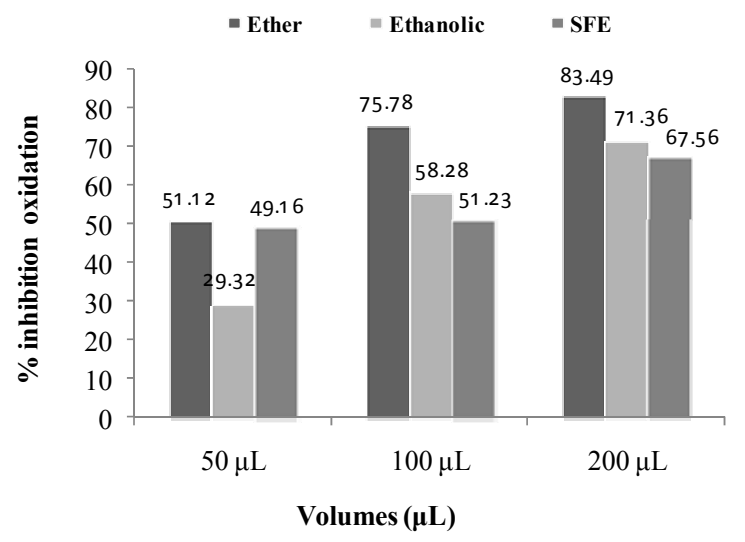

Figure 5: Antioxidant activity of sesame seed extracts (Soxhlet and SFE).

Regarding the extracts obtained by SFE using only $\mathrm{CO}_{2}$ as solvent, 49.16, 51.12 and $67.56 \%$ oxidation inhibition was obtained for the extract volumes of 50, 100 and $200 \mu \mathrm{L}$, respectively. Even though the sesame extracts presented good oxidation inhibition percentages, the method by which the extracts were obtained directly influenced the protection factor against oxidation, as well as the amount of extract, bigger volumes resulting in better results for all samples. Those results are similar to and in accord with the ones previously reported by Mohdaly et al. (2011), Suja et al. (2005) and Xu et al. (2005), who evaluated the antioxidant activity of sesame extracts obtained by the use of $\mathrm{SC}-\mathrm{CO}_{2}$, organic and inorganic solvents. Mohdaly et al. (2011) evaluated the antioxidant activity of sesame extract obtained with methanol as solvent (the polarity of this solvent is very similar to ethanol, used in this study), and obtained as the best result an oxidation inhibition percentage around $70 \%$. Suja et al. (2005) investigated the antioxidant activity of a methanolic extract of sesame and the best inhibition percentage obtained was $46.6 \%$. Xu et al. (2005) evaluated the antioxidant activity of sesame extracts obtained by $\mathrm{SC}-\mathrm{CO}_{2}$, n-hexane and ethanol and found that the antioxidant activity of the ethanolic extract was higher than those of the other two extracts obtained by $\mathrm{SC}-\mathrm{CO}_{2}$ or n-hexane extraction. These results are in good agreement with the ones reported in this study.

Figure 6 displays the kinetic behavior of the Soxhlet and SFE extracts (volume of $200 \mu \mathrm{L}$ ) compared to the control and the synthetic antioxidant BHT.

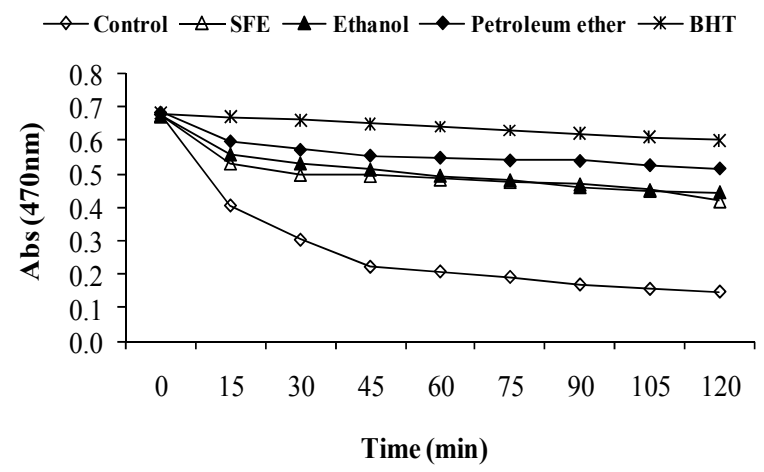

Figure 6: Antioxidant activity of sesame seed extracts and comparison with BHT.

Figure 6 shows that the antioxidant activity in relation to time was very similar for the SFE and alcohol extracts, which indicates that protection with respect to oxidation occurs in a similar manner for both extracts. For the ether extract (petroleum ether), the protection was more effective, which suggests that this method is more adequate for solubilizing the sesame oil antioxidant principles. For comparison, the activity of the synthetic antioxidant BHT was determined at the same concentration used in the extracts and again displayed better inhibition of the oxidative process.

The kinetic factors F1 and F2 were calculated from the data in Figure 6 and are shown in Table 3. Through analysis of the factors, the ether and alcoholic extracts displayed relevant antioxidant kinetic behavior, meaning that the antioxidant compounds present in these extracts are good free radical scavengers, capable of blocking the reaction at the initiation stage. For the SFE extract, good percentages of antioxidant protection were not obtained compared to BHT, especially in terms of the F2 factor, which should represent the action of phenolic compounds on the oxidation propagation step, with the possibility of antioxidant participation in reactions such as the decomposition of hydroperoxides that accelerate the oxidative process. 
Table 3: Kinetic factors $F 1$ and F2 characterizing the oxidation inhibition of the $\beta$-carotene/linoleic acid system by extracts of sesame and by the antioxidant BHT.

\begin{tabular}{|l|l|l|}
\hline Antioxidant & \multicolumn{2}{|c|}{ Factors } \\
\hline Extracts & F1 & F2 \\
\hline Petroleum Ether & 0.3 & 0.6 \\
Ethanol & 0.3 & 0.8 \\
SFE & 0.4 & 1.3 \\
BHT & 0.1 & 0.7 \\
\hline
\end{tabular}

\section{CONCLUSIONS}

Different extraction techniques (Soxhlet and SFE) and different solvents were used to recover the oil contained in sesame seeds.

Regarding the process performance, the Soxhlet technique was more effective $(47.54-58.93 \%)$ than SFE (14.19-26.47\%) at the confidence level adopted $(\mathrm{P}=0.05)$. The highest performance value was obtained by using ethanol as a solvent in the Soxhlet extractor for 8 hours, which took the material to complete exhaustion. For the SFE extraction, the addition of a cosolvent (ethanol) significantly raised $(\mathrm{P}<0.05)$ the sesame oil recovery $(26.47 \%)$ compared to extraction with only $\mathrm{CO}_{2}(14.19 \%)$. Despite the inferior performance, the SFE technique presented very important results, given that, according to the literature, $\mathrm{CO}_{2}$ is a more selective solvent than the organic ones (Bozan e Temelli, 2002) and does not contaminate the final product with solvent residues.

As to the fatty acid profile in the sesame oil, the main components in the all extracts were oleic and linoleic acid. For the Soxhlet extraction, the use of different organic solvents showed that they change the yield of the oil extraction process as well its fatty acid composition, giving statistically different results $(\mathrm{P}<0.05)$. The composition of the oil samples obtained with petroleum ether and ethanol displayed an average of $41.77 \%$ oleic acid, $39.02 \%$ linoleic acid, $9.93 \%$ stearic acid, and $7.91 \%$ palmitic acid. These data are similar to the profile of the fatty acids obtained via SFE, where the mean composition of the samples obtained with and without the use of ethanol was $41.06 \%$ oleic acid, $40.5 \%$ linoleic acid, $11.3 \%$ palmitic acid, and $7.01 \%$ stearic acid. However, the composition data obtained using Soxhlet and supercritical extractions are statistically different at the level of confidence adopted $(\mathrm{P}=0.05)$. Hence, according to the extraction technique used, there will be statistically significant differences in the concentration of fatty acids in the oil obtained.
The sesame oil presented antioxidant activity in all of the extracts. The oxidation inhibition percentage varied from 51.12 to $83.49 \%$ for the ether extract (Soxhlet), 29.32 to $71.36 \%$ for the alcohol extract (Soxhlet) and 49.16 to $67.56 \%$ for the SFE extract (for extract volumes of 50, 100 and $200 \mu \mathrm{L}$ ). For the ether extract (petroleum ether), the protection against oxidation was more effective, what suggests that this is the most adequate method to solubilize the sesame oil antioxidant principles.

Therefore, in view of the results, sesame is an important source of both unsaturated fatty acids and natural antioxidants, confirming its role as an important oleaginous crop for human nutrition.

\section{ACKNOWLEDGEMENTS}

The authors would like to thank the CNPp for financial support and the Biotechnology Laboratory of Natural Polymers (Biopol), Department of Biochemistry of Federal University of Rio Grande do Norte.

\section{REFERENCES}

Abou-Gharbia, H. A., Shahidi, F., Shehata, A. A. Y. and Youssef, M. M., Effects of processing on oxidative stability of sesame oil extracted from intact and dehulled seeds. Journal of the American Oil Chemists Society, 74, n. 3, 215 (1997).

Abou-Gharbia, H. A., Shehata, A. A. Y. and Shahidi, F., Effect of processing on oxidative stability and lipid classes of sesame oil. Food Research International, 33, n. 5, 330 (2000).

Association Official Analytical Chemists, Methyl Esters of Fatty Acids in Oils and Fats, Method 963.22, Washington, AOAC (2000).

Bailey, A. E., Bailey's Industrial Oil and Fat Products. 5th Ed., v. 3, John Wiley: New York (1996).

Borges, M. F. M., Silva, F. A. M. and Ferreira, M. A., Métodos para avaliação do grau de oxidação lipídica e da capacidade antioxidante. Química Nova, 22, n. 1, 94 (1999). (In Portuguese).

Bozan, B. and Temelli, F., Supercritical $\mathrm{CO}_{2}$ extraction of flaxseed. Journal of the American Oil Chemists Society, 79, n. 3, 231 (2002).

Corso, M. P., Klen, M. F., Silva, E. A., Filho, L. C., Santos, J. N., Freitas, L. S. and Dariva, C., Extraction of sesame seed (Sesamun indicum L.) oil using compressed propane and supercritical carbon dioxide. The Journal of Supercritical Fluids, 52, n. 1, 56 (2010). 
Doker, O., Salgin, U., Yieldiz, N., Aydognus, M. and Calimi A., Extraction of sesame seed oil using supercritical $\mathrm{CO}_{2}$ and mathematical modeling. Journal of Food Engineering, 97, n. 3, 360 (2010).

Elleuch, M., Besbes, S., Roiseux, O., Blecker, C. and Attia, H., Quality characteristics of sesame seeds and by-products. Food Chemistry, 2, 641 (2007).

Galvão, E. L., Silva, D. C. F., Silva, J. O., Moreira, A. V. B. and Sousa, E. M. B. D., Evaluation of the antioxidant potential and sub-critical extraction of linseed oil. Ciência e Tecnologia de Alimentos, 28, n. 3, 551 (2008).

Guillen, M. D. and Goicoechea, E., Formation of oxygenated $\alpha, \beta$-unsaturated aldehydes and other toxic compounds in sunflower oil oxidation at room temperature in closed receptacles. Food Chemistry, 111, 157 (2008).

Hemalatha, G. S., Sesame lignans enhance the thermal stability of edible vegetable oils. Food Chemistry, 105, 1076 (2007).

Lichtenstein, A. H. and Deckelbaum, R. J., Stanol/sterol ester-containing foods and blood cholesterol levels. A statement for healthcare professionals from the Nutrition Committee of the Council on Nutrition, Physical Activity, and Metabolism of the American Heart Association, Circulation, 103, n. 8, 1177 (2001).

Lu, B., Zhang, Y., Xiaoqin, W. and Jiayi, S., Separation and determination of diversiform phytosterols in food materials using supercritical carbon dioxide extraction and ultraperformance liquid chromatography-atmospheric pressure chemical ionization-mass spectrometry. Analytica Chimica Acta, 588, 50 (2007).

Marco, G. J., A rapid method for evaluation of antioxidants, Journal of the American Oil Chemists Society, 45, n. 9, 594 (1968).

Mchugh, M. A. and Krukonis, V. J., Supercritical fluid extraction: Principles and practice. Butterworths Heinemann, Boston (1994).

Meireles, M. A. A., Navarro-Diaz, H. J. and Santos, D. T., Phenolic compounds recovery from Punica granatum L. leaves using supercritical $\mathrm{CO}_{2}$. II Iberoamerican Conference on Supercritical Fluids, PROSCIBA (2010).

Miller, H. E., A simplified method for the evaluation of antioxidants. Journal of the American Oil Chemists Society, 48, n. 2, 91 (1971).

Mohdaly, A. A. A., Smetanska, I., Ramadan, M. F., Mohamed A. Sarhan, M. A. and Mahmoud, A., Antioxidant potential of sesame (Sesamum indicum) cake extract in stabilization of sunflower and soybean oils. Industrial Crops and Products, 34, 952 (2011).
Montarini, L., King, J. W., List, G. R. and Rennick, K. A., Selective extraction of phospholipid mixtures by supercritical carbon dioxide and cosolvents. Journal of Food Science, 61, 1230 (1996).

Monteiro, A. R., Meireles, M. A. A., Marques, M. O. and Petenate, A. J., Extraction of the soluble material from the shells of the bacuri fruit with pressurized $\mathrm{CO}_{2}$ and other solvents. Journal of supercritical fluids, 11, 91 (1997).

Moreira, A. V. B. and Mancini Filho, J., Atividade antioxidante das especiarias mostarda, canela e erva-doce em sistemas aquosos e lipídicos. Revista Nutrire, 25, 31 (2003). (In Portuguese).

Moreira, A. V. B. and Mancini Filho, J., Influência dos compostos fenólicos de especiarias sobre a lipoperoxidação e o perfil lipídico de tecidos de ratos. Revista Nutrire, 17, n. 4, 411 (2004). (In Portuguese).

Odabasi, A. Z. and Balaban, M. O., Supercritical $\mathrm{CO}_{2}$ extraction of sesame oil from raw seeds. Journal of Food Science and Technology, 39, 496 (2002).

Official Methods and Recommended Practices of the American Oil Chemistis' Society. 5th. Ed., Champaign, American Oil Chemistis' Society (2004).

Péres, V. F., Saffia, J., Melecchi, M. I. S., Abad, F. C., Jacques, R. A., Martinez, M. M., Oliveira, E. C. and Caramão, E. B., Comparison of Soxhlet, ultrasound-assisted and pressurized liquid extraction of terpenes, fatty acids and Vitamin E from Piper gaudichaudianum Kunth. Journal of Chromatography A, 1105, 115, (2006).

Rodrigues, V. M., Sousa, E. M. B. D., Monteiro, A. R., Chiavone Filho, O., Meireles, M. A. A. and Marques, M. O. M., Determination of the solubility of the extracts from vegetable raw material in pressurized $\mathrm{CO}_{2}$ : a pseudo ternary mixture formed by cellulosec structure + solute + solvent. Journal Supercritical Fluids, 22, 21 (2002).

Siger, A., Nogala-Kalucka, M. and LampartSzczapa, E., The content and antioxidant activity of phenolic compounds in cold-pressed plant oils. Journal of Food Lipids, 15, 137 (2008).

Sousa, E. M. B. D., Chiavone Filho, O., Moreno, M. T., Silva, D. N., Marques, M. M. and Meireles, M. A., Experimental results for the extraction of essential oil from Lippia sidoides cham. using pressurized carbon dioxide. Brazilian Journal of Chemical Engineering, 19, n. 2, 229 (2002).

Sousa, E. M. B. D., Martinez, J., Chiavone Filho, O., Rosa, P. T. V., Domingos, T. and Meireles, M. A. A., Extraction of volatile oil from Croton Zehntneri Pax et Hoff with pressurized $\mathrm{CO}_{2}$ : 
Solubility, composition and kinetics. Journal of Food Engineering, 69, n. 3, 325 (2005).

Sovova, H., Zarevucka, M., Vacek, M. and Stransky, K., Solubility of two vegetable oils in supercritical $\mathrm{CO}_{2}$. Journal of Supercritical Fluids, 20, n. 1, 15 (2000).

Suja, K. P., Jayalekshmy, A. and Arumugha, C., Antioxidant activity of sesame cake extract. Food Chemistry, 91, 213 (2005).

Tanaka, Y., Sakaki, I. and Ohkubo, T., Extractions of phospholipids from Salmon Roe with supercritical carbon dioxide and an entrainer. Journal of Oleo Science, 53, 417 (2004).
Visavadiya, N. P., Soni, B. and Dalwadi, N., Free radical scavenging and antiatherogenic activities of sesamum indicum seed extracts in chemical and biological model systems. Food and Chemical Toxicology, 47, 2507 (2009).

$\mathrm{Xu}$, J., Chen, S., Hu, Q., Antioxidant activity of brown pigment and extracts from black sesame seed (Sesamum indicum L). Food Chemistry, 91, 79 (2005).

Yanishlieva, N. V. I. and Marinova, E. M., Effects of antioxidants on the stability of triacyglycerols and methyl esters of fatty acids of sunflower oil. Food Chemistry, 54, n. 4, 377 (1995). 